Volume 3

Number 4 Critical Perspectives on Marketing

from Japan - Part 2

2018

\title{
A Critical Marketing Practitioner in Japan: Philosophy and Marketing Activities of Seiji Tsutsumi
}

Kazuo Usui

Saitama Gakuen University

Follow this and additional works at: https://digitalcommons.uri.edu/mgdr

Part of the Anthropology Commons, Economics Commons, Marketing Commons, Other Business Commons, and the Sociology Commons

\section{Recommended Citation}

Usui, Kazuo (2018) "A Critical Marketing Practitioner in Japan: Philosophy and Marketing Activities of Seiji Tsutsumi," Markets, Globalization \& Development Review. Vol. 3: No. 4, Article 2.

DOI: 10.23860/MGDR-2018-03-04-02

Available at: https://digitalcommons.uri.edu/mgdr/vol3/iss4/2

This Article is brought to you for free and open access by DigitalCommons@URI. It has been accepted for inclusion in Markets, Globalization \& Development Review by an authorized editor of DigitalCommons@URI. For more information, please contact digitalcommons-group@uri.edu. 


\section{A Critical Marketing Practitioner in Japan: Philosophy and Marketing Activities of Seiji Tsutsumi}

\section{Cover Page Footnote}

This is an author-approved and author-initiated adaptation of the paper originally published in the Conference on Historical Analysis and Research in Marketing (CHARM) Proceedings. The MGDR version is updated and adjusted for this journal's style. MGDR editor Nikhilesh Dholakia provided help with MGDR style transformation. 


\section{Markets, Globalization \& Development Review}
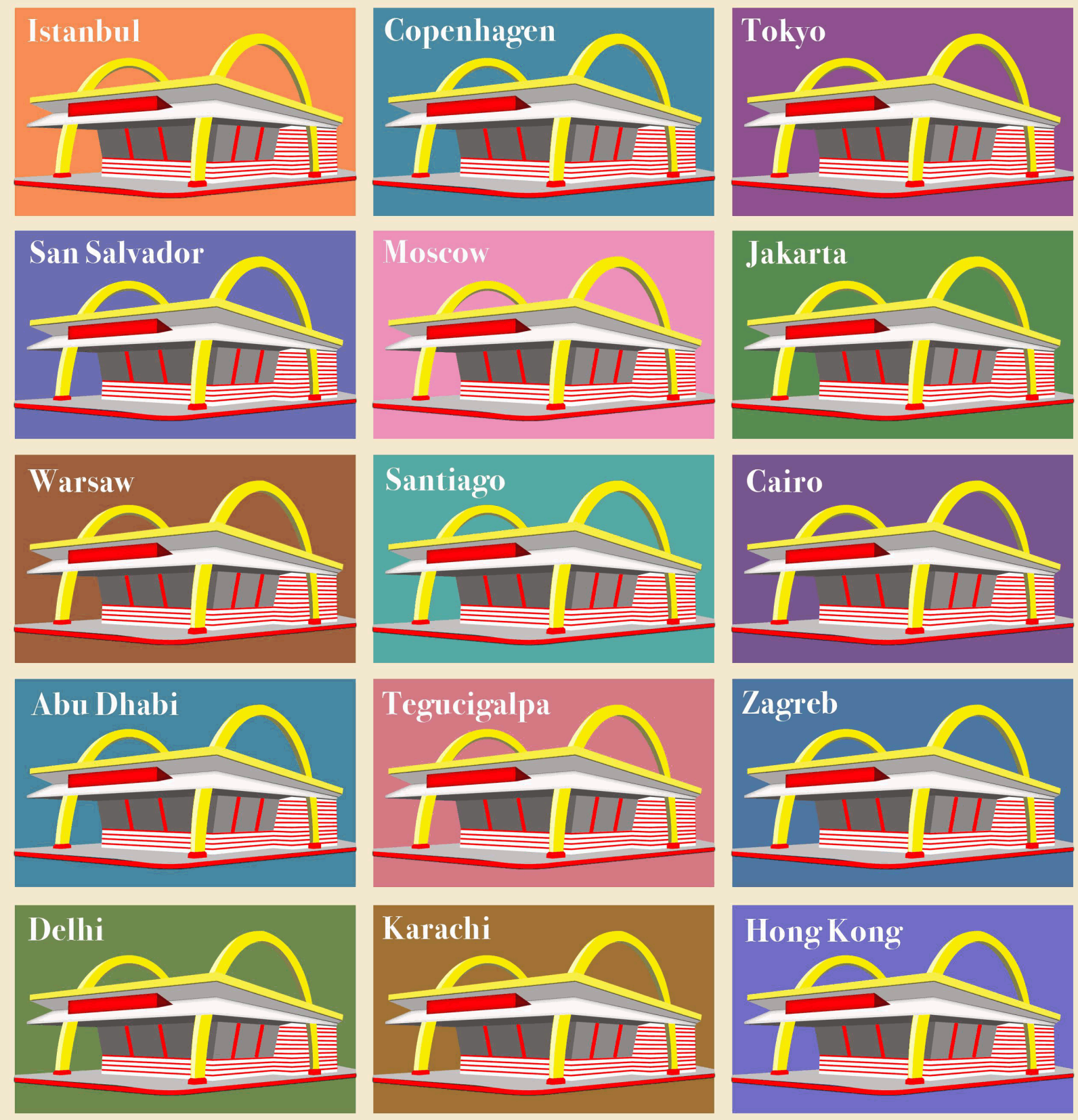

This article is available in Markets, Globalization \& Development Review: https://digitalcommons.uri.edu/mgdr/vol3/ 


\title{
A Critical Marketing Practitioner in Japan: Philosophy and Marketing Activities of Seiji Tsutsumi
}

\begin{abstract}
Introduction
Dr. Seiji Tsutsumi (1927-2013) was a prominent executive in the Japanese retail and service industries, and - at the same time - a critical thinker in marketing, consumer culture and politics in Japan. He was also a famous poet and novelist in Japan, writing under the pseudonym Tsujii Takashi. As a poet and novelist, writing under this name, he was awarded several literary prizes. Whenever he was involved in business and its criticism, however, he gave his real name. Despite establishing a very large business group representing Japan composed of department stores, superstores, shopping centres, convenience stores, specialty stores, and many service companies Seiji Tsutsumi retained a critical attitude to marketing and consumer society. This article focuses on his criticism of business, society and consumer society; and gives a historical interpretation of his critical marketing views.
\end{abstract}

\section{Background and Marketing Activities}

Seiji Tsutsumi was born into a wealthy family. His father, Yasujiro Tsutsumi (1889-1964), made a fortune by developing real-estate and railway businesses before the Second World War. Yasujiro became a member of the House of Representatives before and after the Second World War and its Speaker after the War (Havens 1994; Yui, Maeda and Oikawa 1996). A feud against father was one of the main motifs of Seiji Tsutsumi's novels - of course, written under the assumed literary pseudonym (e.g., Tsujii 2004; see Yui 2014).

When Seiji Tsutsumi was a student of the Faculty of Economics, Tokyo University in the late 1940s, he got involved in the left-wing movement. Under the political upheaval in Japan soon after the Second World War, he became a member of the Japan Communist Party in 1949, but was ousted next year due to severe struggles between the factions inside the Party (Ando 1976). After recuperating from tuberculosis, he became a private political secretary of his father, and got engaged in Seibu Department Store on his father's orders in 1954. This store was located in lkebukuro, a non-rich area of Tokyo famous for black markets after the War. When he accepted his father's appointment, he raised two stipulations with his father: setting up the labor union in this company and recruiting university graduates (Tsujii and Ueno 2008, pp. 28-29); both were rare in retail business at the time. This can be seen as the start of his philosophy of business, what he 
later called 'a republican form of management (keiei kyowa-sei)' (see Havens 1994; Yui 2010).

Seiji Tsutsumi's business and marketing activities had two fundamental features. First, his businesses developed rapidly and remarkably along with miraculous economic growth from 1955 to 1973 in Japan, and the appearance of the so-called mature economy as a result of this economic growth. He developed networks of many retail formats, including Seibu Department Store, Seiyu Store (from 1956, later simply called Seiyu) as a Japanese-type superstore or what the Japanese called 'general super' (see Usui 2014), Family Mart (from 1978) as a convenience store, Parco as a fashionable shopping center, and Muji as a world famous specialty store with a global reach (see Holloway and Hones 2007). Indeed, Holloway and Hones (2007) offer a well-crafted spatio-cultural analysis of Muji stores, showing the hybridity of various forms and levels of mundaneness and sophistication - in terms of store design, item selection, and understated (anti-establishment?) sophistication of the Muji shoppers.

In addition to these retail developments, he also expanded his businesses to the service sectors, such as Restaurant Seibu (from 1974), Seibu Urban Development (from 1972, later Seiyo Environment Development), Seibu Credit (from 1980, later Credit Saison), Seibu Allstate Life Insurance (from 1975, in alliance with the Allstate insurance arm of Sears Roebuck), Intercontinental Hotels (from 1988) and so forth.

In the process of this development, Seiji Tsutsumi established a company group named the Seibu Distributive Group (Seibu Ryutsu Group) in 1971, and changed it to the Saison Group in 1985 because the group was no longer categorized as a 'distributive industry (ryutsu sangyo)', a term that restrictively suggested retail of tangible products. The concept of 'comprehensive life industry (seikatsu sogo sangyo)', which meant the group would be involved in any dimensions of consumers' life, became the main philosophy of this group (Saison Corporation 1992). The member companies of the Saison Group grew to 141 under the control of 12 main companies in 1989/90 (Koyama 1991, pp. 390-391). The name of Seiji Tsutsumi came to symbolize a huge business group representing Japan.

Secondly, and more importantly, Seiji Tsutsumi tried to make his retail/service businesses culture-oriented from the outset. For Seibu Department Store, he invited French designers including Louis Feraud (1959), Ted Lapidus (1960) and Yves Saint-Laurent (1963). In the 1960s, Seibu Department Store also held fine art events including the Paul Klee Exhibition, the Salvador Dalí Exhibition, the German Expressionism Exhibition, the Henri Rousseau Exhibition, the Fernand Léger Exhibition, and so forth. The success of these events led to the establishment of the Seibu Museum of Art inside the Seibu Department 
Store in 1975.

In 1969, he opened a fashionable shopping center, Parco, directed by his friend, Tsuuji Masuda (1926-2007), by buying the neighboring building of Seibu Department Store and organizing a combination of many fashionable shops targeting stylish younger generations. In 1968 and 1973, Seibu Department Store and Parco established themselves in Shibuya Tokyo, which had some wealthy, quiet areas but was occupied by a strong competitor, Tokyu Department Store. Parco in Shibuya started Seibu Theatre (later Parco Theatre) with about 500 seats inside the building, where musicals and plays began to be staged even before the opening of Shibuya Parco itself. Park Avenue (Koen Dori) leading to Parco, the town Shibuya, and what was called Parco Culture became a sign of fashion-oriented consumer culture in the 1980s, as indicated by many commentators (e.g., Kitada 2002; Miura 2006; Yoshimi 2008).

In the meantime, Seiji Tsutsumi introduced a new retail format called 'Mujirushi Ryohin', meaning high-quality goods with no brand, in 1983. This became known as Muji outside Japan. The idea originally began as a private brand for Seiyu, a chain of superstores in the Seibu group, in 1980. Tsutsumi defined that the concept of Muji or Mujirushi Ryohin should seek, firstly, an anti-establishment ideology, secondly, a consistent image (minimalistic and simple but artistic designs, as 'muji' in Japanese connoted plainness), and thirdly, economy-oriented goods (Koyama 1991, p. 464, see also Yui, Tatsuki and Ito 2010, p. 88). Seiji Tsutsumi intensified the concept of anti-establishment products. He explained later, 'It was quite difficult to penetrate the idea into the company, no matter how I emphasized that these products were oriented to anti-establishment. ... When the concept of 'anti-establishment' is broken down, it is composed of two aspects. First, the objection to the American-style affluence that almost all people aspire to. Another is the rejection of fashions and vogues, although there are plenty of fashions and vogues on the streets nowadays; and this should be a cool attitude in the end. Anti-American prosperity and anti-vogues are the two main "anti" factors' (Tsutsumi and Miura 2009, p. 97 and 99). Almost 7,000 items Muji provided were plainly designed, and not oriented to convenience, luxury or waste. Rather, 'we provide the products as if half-completed ones; then please think about how to use them yourself' (Tsutsumi and Miura 2009, p. 100). The idea can be seen as consistent with his criticism of consumer society explored below.

Despite the prosperity of his business, the Saison Group had to be dissolved due to severe financial problems in 2001. Yui, Tatsuki and Ito (2010, p. 18, 31 and 40$)$ analyzed this failure and suggested that Seiji Tsutsumi's organizational philosophy, 'a republican form of business (keiei kyowa-sel)' which was to avoid hierarchical dominance 
by the core companies over the member companies, and 'a rhizome-like organization (rhizome-gata soshiki)' in which each independent company freely shared ideas and connected with each other underground, rather overlooked the situation where nobody knew or controlled the whole body of the Saison Group that expanded so widely. As a result, the burst of the so-called 'bubble economy (1986-1991)' exposed huge deficits of member companies. In particular, the losses of Tokyo City Finance, a nonbank financial company, and Seiyo Environment Development, a company for development of real estate, were too huge to be compensated. This problem led to the dissolution of the Saison Group 1999 to 2003, and Seiji Tsutsumi compensated by giving his whole fortune. After this event, he never returned to the business world, while he continued the activities of a poet and novelist and an active political commentator.

\section{Critical Thinking of Marketing and Consumer Culture}

Seiji Tsutsumi continued to keep a critical mindset both as an activist of the left-wing movement and as a successful executive in business. He recollected:

Whether the organization is a bureaucratic office or a private enterprise ... it imprisons people in non-humanistic or de-humanistic faces. People tend to obey the orders of the organization by repressing their objections based on their true sensitivity.

We can replace the term 'organization' here with 'revolutionary ideas' or the performance of 'what you ought to be (Sollen)'.

When I was a member of the revolutionary party, I repressed the objections welling up from inside myself as they were caused by the vestige of my petit bourgeois feelings, and tried to overcome these objections to become a real revolutionary.

When I tried to continue to be an executive, I also turned down the objections that sprung from my sensitivity by using as leverage what I ought to do for companies' profits and not being defeated by strong competitors (Tsutsumi 2000, pp. 30-31).

Seiji Tsutsumi tried to theorize his objections while he was a famous executive of the retail and service businesses. His efforts produced two theoretical books, A Perspective Drawing for Changes (1979, rev. ed. 1985) and Criticism of Consumer Society (1996).

The first book discussed the essential feature of the distributive industry. According to him, 'the distributive industry exists on the boundary between the theory of capitalism and the theory of humanity'. 'The distributive industry has two contradictory features; it has the features that must be industrialized to this point, and must not be 
industrialized from this point'. In this sense the distributive industry is essentially 'the marginal industry' (1979, p. 344; 1985, p. 301).

Based on the theory of capitalism, the distributive industry should be modernized and industrialized. Thus, the idea of 'the revolution of distribution (ryutsu kakumei)', 'the revolution of the distributive industry (ryutsu sangyo kakumei)' and 'the information revolution of distribution (ryutsu joho kakumei)' successively appeared in Japan from the early 1960s onwards, and modern retail formats such as supermarkets, superstores and chain stores were introduced on a large scale and carried out the system of mass distribution and mass consumption based on the mass production. With this theory of capitalism, there materialized an affluence society in Japan, involving modernization, rationalization, standardization and the increasing economies of scale on the one hand; and diversification in the marketspace on the other hand. Nevertheless, this state of affairs - in Japan and globally - is distant from 'the individualistic process of life of a human being' which Karl Marx defined as the essence of consumption (Tsutsumi 1985, pp. 309-310).

This question induced him to publish the second book, Criticism of Consumer Society, which won him the title of Doctor of Economics from Chuo University. The aim of this book is 'deconstruction of the concept of consumption', which was vaguely expressed as 'the theory of humanity' in the former book.

In the so-called consumer society, the act of consumption itself is the target of manipulation by capitalism as features that constitute the relationships within the market.

As the twentieth century is known as 'the century of advertising agents and theme parks', marketing supporting these activities is just a skill to sell the products that are produced massively, and is in turn a skill to direct and commercialize the signs of consumption. To tell the truth, the society called 'consumer society' is merely the society for producers, and the society representing the direction of market trends by capitalism. In order to change a paradigm of the industrial society, the phase of marketing should also be fundamentally changed.

In order to criticize consumer society from the current perspective of global society and to reorganize the paradigm of the industrial society, we should get back to the fundamental meaning of consumption to exclude representation of consumption with symbols, and establish the fundamental concept of consumption as realization and fulfilment of the self (Tsutsumi 1996, pp. 24-25). 
Thus, Seiji Tsutsumi critically explored the concept of 'developmentalism' in the Japanese economy, expressions of symbols in advertisements, consumption of signs, and differentiation of images, and changes in Japanese-style management, by mobilizing his extensive knowledge of theorists such as Friedrich Hegel, Karl Marx, Adam Smith, Jean Baudrillard, Roland Barthes, Karl Polanyi, and many Japanese philosophers. His theoretical exploration inevitably included self-criticism. 'This book is a criticism of industrial society based on my experiences, and also a criticism of myself who was involved in this society as an executive' (Tsutsumi 1996, p. 205).

While self-criticism by a successful executive left many people puzzled, it can be said that his self-criticism was an attempt to go beyond the critiques which some serious commentators aimed at Saison Group marketing. They indicated, for instance, 'Park Avenue in Shibuya became an advertised and commercialized space as a result' of Parco's marketing (Miura 2006, p. 127); 'we cannot review the current art scene in Japan except the Seibu Museum, the Art Vivant, and Parco Publication, which are, in a broader sense, all advertising media for Seibu' (Watanabe [1986] 2012, p. 185); and 'any culture and art become kinds of advertising when they have the backing of Saison Group' (Miura 1991, p. 445). Seiji Tsutsumi himself tended to welcome this type of criticism, and his second book can be seen as an attempt to extend this criticism.

Nevertheless, while his second book was exploring many criticisms of capitalistic marketing and consumption, he could not push what he considered as the desirable consumption patterns and marketing thought to the front of his thinking. He could only suggest some clues. Seiji Tsutsumi preferred to collect first-class economists, management theorists and academics in many other fields, but his contact with the Macromarketing School was only primitive. He was invited to a conference on marketing and development in 1995 and met a few US macromarketing scholars for the first time. Mentioning the names of Nikhilesh Dholakia and Fuat Firat, he noted his impression: 'The Conference on Marketing and Development, which invited these scholars and was held at Saitama University in July 1995, should be memorized as a prior notice of the arrival of a new era of marketing study' (Tsutsumi 1996, p. 232, fn.2). As such he clearly recognized the critical side of macromarketing as 'a new marketing thought' (Tsutsumi 1996 , p. 193). It is no longer clear whether his criticism could have developed further if he had contacted many macromarketing scholars in depth.

\section{Concluding Observations}

Seiji Tsutsumi raised a fundamental question in his later years, 'Can we call the society in which only secular desires are satisfied a utopia?' 
(Tsutsumi 2000 , p. 211). As this query suggested, he continued to be an idealist, a dreamer and a criticism-minded figure even though he was expelled from the left-wing movement and became a representative executive (Nikkei Ryutsu Newspaper 1996). Seiji Tsutsumi was a unique critical marketer in Japan, and his search for the 'ethics of capitalists' (Yomiuri Newspaper 1997) influenced the Japanese business and marketing world. Applied disciplines like marketing could benefit by moving forward along the path of critical thinking - blending insights from practices and the world of theory - about marketing and consumption phenomena, a path to which Seiji Tsutsumi devoted his life. 


\section{References}

Ando, Jinbe (1976), A Personal Record of the Japan Communist Party after the Second World War [Sengo Mihon Kyosan-to Shik]. Tokyo: Gendai no Riron-sha (in Japanese).

(The) Editorial Committee of the History of the Saison Group (1991), The Activities of Saison: A Collection of Chronological Tables and Historical Materials [Saison no Katsudo: Nenpyo, Shiryo-shu]. Tokyo: Libro Port (in Japanese).

Havens, Thomas (1994), Architects of Affluence: The Tsutsumi Family and the Seibu Enterprises in Twentieth-Century Japan. Cambridge, MA: Harvard University Press.

Holloway, Julian, and Sheila Hones (2007), "Muji, materiality, and mundane geographies." Environment and planning a 39, no. 3: $555-69$.

Kitada, Akio (2002), Tokyo as an Advertising Metropolis: Its Birth and Death [Kokoku Toshi tokyo: Sono Tanjo to Shi]. Tokyo: Kosei-do Shuppan. (in Japanese)

Koyama, Shuzo (1991), 'Mature Market and the Saison Group', in Yui, Tsunehiko (ed.), The History of Saison [Saison no Rekishi], Part II, Tokyo: Libro Port, pp. 369-635. (in Japanese)

Miura, Atsushi (2006), 'Anxious Self' in the 'Age of Freedom': Deconstruction of Consumer Society ['Ziyu na Jidai' no 'Fuan na Jibun': Shohi Shakai no Datsu-kochiku]. Tokyo: Shobun-sha (in Japanese).

Miura, Masashi (1991), 'A live paradox: criticism to strategy of culture and art', in Ueno, Chizuko et al. (eds.), A Saison's Way of Thinking [Saison no Hasso], Tokyo: Libro Port, pp. 341-467 (in Japanese).

Nikkei Ryutsu Newspaper (1996), 'President of Saison Corporation Seiji Tsutsumi: Cannot put his heart and soul to the capitalist theory', Nikkei Ryutsu Newspaper [Nikkei Ryutsu Shinbun], 11th January (in Japanese).

Saison Corporation (ed.) (1992), The Comprehensive Life Industry [Seokatsu Sogyo Sangyo-ron]. Tokyo: Libro Port (in Japanese).

Tatsuki, Mariko (1991), 'The distribution revolution and the formation of the Seibu Distributive Group', in Yui, Tsunehiko (ed.), The History of Saison [Saison no Rekishi], Part I, Tokyo: Libro Port, pp. 237-378 (in Japanese).

Tsujii, Takashi (2004), A Portrait of Father [Chichi no Shozo]. Tokyo: Shincho-sha (in Japanese). 
and Chizuko Ueno (2008), A Future of the Post-Consumer Society [Posto Shohi Shakai no Yukue]. Tokyo: Bunshun Bunko (in Japanese).

Tsutsumi, Seiji (1979), A Perspective Drawing for Changes: From the Perspective of the Distributive Industry [Henkaku no Toshizu: Ryutsu Sangyo no Shiten Kara]. Tokyo: Nihon Hyoron-sha (in Japanese).

(1985), A Perspective Drawing for Changes: Ideas for the Post-Distributive Industry [Henkaku no Toshizu: Datsu-Ryutsu Sangyo Ron]. Rev. ed., Tokyo: Libro Port (in Japanese).

(1996), Criticism of Consumer Society [Shohi Shakai Hihan], Tokyo: Iwanami Syoten (in Japanese).

(2000), The Death of Utopias [Utopia no Shometsu], Tokyo: Shueisha Shinsyo (in Japanese).

and Miura, Atsushi (2009), Muji Japan: The Death of the 20th Century-Style Consumer Culture [Mujirushi Nippon, 20-seiki gata Shohi Shakai no Shuen]. Tokyo: Chuko Shinsyo (in Japanese).

Usui, Kazuo (2014), Marketing and Consumption in Modern Japan. Abingdon, Oxon: Routledge.

Watanabe, Yutaka ([1986] 2012), The Birth of Audiences: Music Culture in the Postmodern Era [Choshu no Tanjo: Postmodern Zidai no Ongaku Bunka]. Tokyo: Chuko Bunko (in Japanese).

Yomiuri Newspaper (1997), 'Interview: Considering with Seiji Tsutsumi, Ask again the ethics of capitalists', Yomiuri Newspaper [Yomiuri Shinbun] 7th November 1997 (in Japanese).

Yoshimi, Shunya (2008), Dramaturgy of Metropolises [Toshi no Doramatsurugi]. Tokyo: Kawade Shuppan Shinsha (in Japanese).

Yui, Tsunehiko (1991), 'From Musashino Department Store to Seibu Department Store', in The History of Saison [Saison no Rekishi], Tsunehiko Yui, ed. Part I, Tokyo: Libro Port, pp. 1-72 (in Japanese).

(2010), 'Philosophy of Saison and formation of a company group', in Collapse and Reconstruction of Saison [Seison no Zasetsu to Kaitai], Tokyo: Sanai Shoin, pp. 3-32 (in Japanese).

(2014), 'A retrospect on a life of going for broke: a memory of the late Seiji Tsutsumi', Eureka [Yuriika], 46 (2), February, pp. 91-96 (in Japanese).

Maeda, Kazutoshi and Oikawa, Yoshinobu (1996), Yasujiro 
Markets, Globalization \& Development Review, Vol. 3 [2018], No. 4, Art. 2

Tsutsumi [Tsutsumi Yasujiro]. Tokyo: Libro Port (in Japanese).

Mariko Tatsuki and Osamu Ito (2010), Collapse and Resuscitation of Saison [Saison no Zasetsu to Saisel]. Tokyo: Sanai-shoin (in Japanese). 